\title{
Un pueblo michoacano visto desde la fotografía
}

\author{
Arturo Vaca Munguía y Yaminel Bernal Astorga
}

LUIS RAMÍREZ SEVILLA, 2002

\section{Villa Jiménez en la lente de Martiniano}

\section{Mendoza. Fotografía y microhistoria} de un pueblo michoacano

El Colegio de Michoacán, Zamora, Michoacán, México.

\footnotetext{
【 $\begin{aligned} & \text { a fotografía como testigo de lo } \\ & \text { que se fue y de lo que aún se }\end{aligned}$ conserva. El "eso ha sido"l bien podría ser una de las sugerencias que Luis Ramírez propone a los lectores con relación a cómo mirar la obra fotográfica de Martiniano Mendoza. Estas páginas son, a su vez, pretexto, o me-
}

${ }^{1}$ Cfr. Roland Barthes, La cámara lúcida. Nota sobre la fotografia, Paidós, Barcelona, 1999, p. 207. jor dicho, invitación a conocer otras miles de imágenes más que se encuentran en cajas de zapatos dentro de la casa del fotógrafo en Villa Jiménez, Michoacán. Sin embargo, debemos aclarar de antemano que el "eso ha sido" abordado por el autor no es el "esto quiere decir"2 del propio Marti-

${ }^{2}$ Cfr. Phillipe Dubois, El acto fotográfico de la

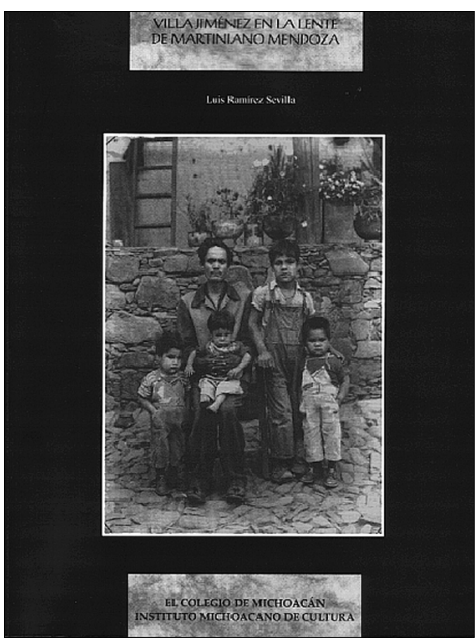

niano o de las personas retratadas en las fotografías.

Luis Ramírez presenta un pueblo a través de imágenes enmarcadas en el periodo histórico que va de $1940 \mathrm{a}$ 1960. Estas imágenes atestiguan lo que Martiniano captó como personaje de su tiempo. Con su lente, por oficio y por gusto, guardó testimonios de la cotidianidad al retratar diferentes aspectos del lugar donde le tocó vivir ${ }^{3}$.

representación a la recepción, Paidós, Barcelona, 1994, p. 191.

${ }^{3}$ Una de las características distintivas de estos

\section{A Village in Michoacán Seen Through Photography}

ARTURO VACA Munguía Y YAMINEL Bernal ASTORGa: El Colegio de Michoacán, Zamora, Michoacán, México.

<artvac@colmich.edu.mx $><$ bernal@colmich.edu.mx $>$

Las fotografías que se presentan en este artículo fueron tomadas del libro aquí reseñado.

ฉ. Desacatos, núm. 26, enero-abril 2008, pp. 169-173. 
Cuando se muestra una serie de fotos es necesaria una explicación de las circunstancias propias de cada una de las imágenes. Ramírez cumple con esa función y nos ofrece estas efigies para despertar el deseo de conocer las otras, y como invitación a rescatar el archivo completo 4 .

El autor resalta también la importancia de este tipo de archivos para las ciencias sociales, y dice: "Este volumen es un intento por conocer y apreciar el cambio social y cultural que vivió un pueblo rural en una etapa importante de su historia, a través de un archivo fotográfico excepcional que se presta especialmente para este ejercicio" (p. 15).

Para esto hace falta algo más que presentar únicamente una serie de fotos; es necesario aportar una perspectiva más amplia, lo cual hace Ramírez con información escrita de manera sencilla; nos introduce en el contexto, lo que permite enmarcar las fotografías ${ }^{5}$. Sabemos así que fueron tomadas en un lugar específico, perfectamente localizado, que se organiza como municipio en 1921. En la actualidad Villa Jiménez se encuentra alejado de los caminos principales, pero en su tiempo estaba comunicado con el antiguo camino real que iba de

archivos es la mirada que proporcionan, pues son testimonios directos de su tiempo, sin excluir la intencionalidad del fotógrafo. ${ }^{4}$ Se dan a conocer aproximadamente cien fotos, en comparación con los más de 20 mil negativos que se conservan.

5 El texto guía nuestra mirada, evitando la interpretación fácil de alguien que ante una imagen simplemente comienza a elucubrar en busca de razones y explicaciones que den cuenta de lo que mira.
México a Guadalajara. Otra característica fundadora del pueblo es la migración — ejemplo de ello es el propio don Martiniano-: Villa Jiménez fue un lugar donde se establecieron personas de múltiples orígenes, que venían cargados de tradiciones, fiestas y hasta con un santo a cuestas. Es así como aparecen los coloquios, las danzas de San Nicolasito y el fusilamiento de Judas.

Después de relatar el origen del municipio, Ramírez nos sitúa en la década de 1940, es decir, en la Villa Jiménez que conoció Martiniano. El autor parte de diversas voces, desde los recuerdos de algunos villanos, las descripciones que dejó en su tesis un médico de la época (Armando Loaiza ${ }^{6}$ ), hasta información recopilada en los archivos municipales.

Lo que sigue es una propuesta de clasificación del archivo de Martiniano, en cuatro categorías: 1) familias y amigos; 2) ceremonias del ciclo vital; 3) escenarios abiertos y grupos no familiares, y 4) documentos y otros. Ramírez nos advierte que encontraremos fotos en las que predominan las mujeres, distinción de género que corrobora de manera visual la importancia de la migración, principalmente de los hombres a Estados Unidos 7 . También es de destacar la serie de

\footnotetext{
6 Luis Ramírez recoge una serie de citas de la tesis de Loaiza que permite ver el extrañamiento y la manera en que un médico de la época, venido de la capital del país, observaba la localidad rural donde le tocó hacer su servicio.

7 Un doble testimonio de la migración y el género es la vestimenta; en particular, los pantalones de pechera (overoles) con los que se encuentran ataviados principalmente los niños
}

retratos de difuntos, sobre todo de los niños - "la muerte niña", como la refiere el autor-, costumbre popular que permitía conservar, de alguna manera, el recuerdo del infante falleci$\mathrm{do}^{8}$. En esa época y en ese lugar en concreto - como deja constancia Luis Ramírez-, la mortalidad infantil presentaba índices elevados, por lo que retratar a los muertos era una de las actividades laborales de Mendoza.

Cuando creemos haber dejado atrás el texto y nos encontramos entregados a la contemplación de las fotografías de Martiniano, volvemos a toparnos con las explicaciones de Luis Ramírez hacia la página 153 (como quien nos alcanza y nos dice: "Se me olvidaba decirles, faltan estas fotos"). Este apartado, dedicado al cambio y a las transiciones del pueblo, pone énfasis en los procesos que lo modificaron: las fiestas y tradiciones, las escuelas, los sucesos políticos, algunos indicadores, signos precursores del progreso que llega ${ }^{9}$, además de las fotos de ciertos documentos con el fin de atestiguar o de salvaguardarlos en tiempos anteriores a las fotocopias. Estas referencias puntuales y atinadas se vuelven imprescindible para entender las

varones, y los vestidos y las trenzas de las niñas.

${ }^{8}$ Por lo sui generis del tema y su reproducción en otros lugares del país, el autor ofrece en las páginas 60-64 una revisión del asunto. ${ }^{9}$ Cada uno de estos temas constituye un eje de análisis de los procesos y los caminos que se siguieron en la construcción, transformación y ocaso de una comunidad, en la que pareciera continuarse el círculo de andanzas de los nómadas que un día decidieron que Villa Jiménez era un buen lugar para vivir y luego, paulatinamente, lo abandonaron. 


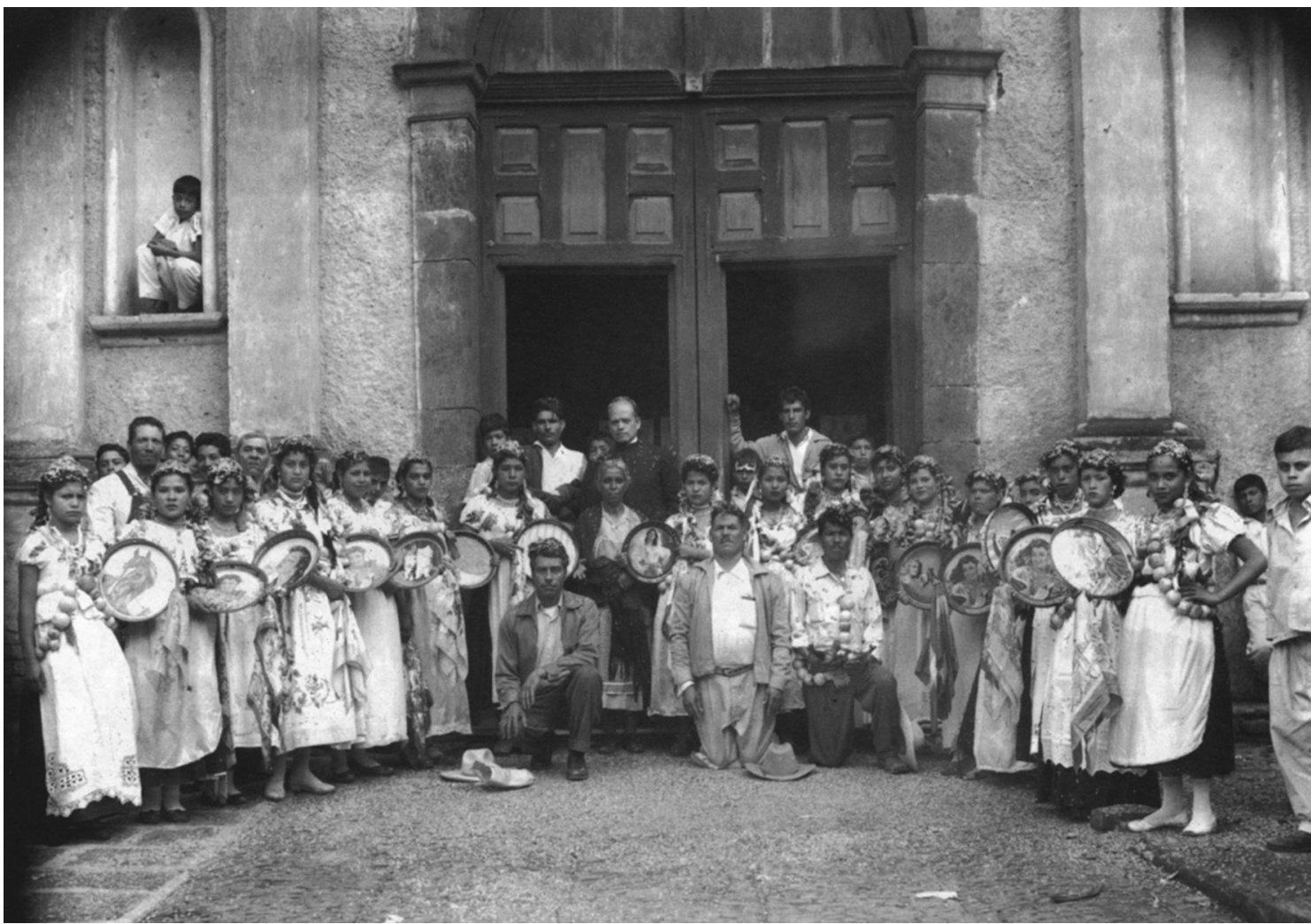

imágenes que siguen y con las que termina el libro.

Los cambios sociales que se dan en el tiempo pueden observarse en las imágenes ${ }^{10}$ : las variaciones de la moda y los hábitos, patentes, por ejemplo, en el peinado de las mujeres (de trenzas a bucles) o en la vestimenta de los hombres (de overol, sombrero y pistola a traje, casimir y mocasín). Igualmente se aprecian los nuevos implementos agrícolas, las variaciones en las construcciones, la presencia de vehículos como testigos de los procesos de

\footnotetext{
10 También son visibles las continuidades; por ejemplo, el vidrio roto de la escuela del que haremos mención más adelante.
}

transformación del mundo que los villanos construyeron a lo largo de décadas. El cambio también se manifiesta en los retratos de grupos familiares: en las fotos más antiguas, las mujeres y los hombres aparecen separados, con patentes diferencias entre ellos; en las imágenes más recientes, la composición de los grupos es más heterogénea ${ }^{11}$.

Otro aspecto relevante es que el uso de la fotografía ha variado con el tiempo. Por ejemplo, ya no se retrata a los muertos, quizás como reflejo de

${ }^{11}$ Las fotos de familias de Villa Jiménez (pp. 82-87) y la convivencia en la casa y el campo (pp. 118-122) son un ejemplo de esto. la disminución de las tasas de mortandad $^{12}$. De igual manera, se desistió de tomarse fotos con animales en el estudio. Además, el uso de cámaras automáticas como parte de las innovaciones técnicas de la época originó la disminución de la actividad del fotógrafo, abriendo la posibilidad de "la democratización de la efigie"13.

Las fotografías se presentan en dos series generales. La primera (pp. 65-

\footnotetext{
12 Aun cuando este hecho no lo destaca el autor, esta tendencia se dio en todo el país hacia la década de 1960.

${ }^{13}$ Citado por el autor: Carlos Monsiváis, Foto estudio Jiménez. Sotero Constantino, fotógrafo de Juchitán, Era, Ayuntamiento Popular de Juchitán, México, 1984.
} 
152) comprende las colecciones que corresponden a dos de las categorías utilizadas en la clasificación del archivo: en primer lugar se encuentran las familias y los amigos. Este grupo está integrado por las familias de Villa Jiménez, las niñas y niños del lugar que posan en el estudio, la gente de Jiménez y sus animales y, finalmente, la convivencia en casas y en el campo. En esos apartados se reúnen diversos retratos que muestran la manera como los villanos deseaban perpetuarse o conservar su recuerdo. Sobresale, en el caso de los hombres, la puesta en escena de accesorios que implicaban la hombría y con los que reforzaban su virilidad: la pistola, la botella, el cigarro, el sombrero de lado, etc. También se observan mujeres y niños formando familias en las que el padre no está presente, ausencia atribuida por el autor a la migración del jefe de familia hacia Estados Unidos. Esta primera serie de fotos constituye el testimonio de un pueblo mestizado. Aparecen ceremonias del ciclo vital, comuniones, bodas, entre otros aspectos de la vida social de los habitantes de Villa Jiménez. De igual forma, se exponen también las situaciones no festivas, es decir, los decesos (del templo al camposanto), imágenes entre las que destaca la serie llamada "La muerte niña".

Respecto al estilo fotográfico de don Martiniano en esta primera serie de fotografías, es necesario tomar en cuenta las condiciones de tiempoespacio; en particular el difícil acceso a los avances tecnológicos en esta materia tanto por razones de alejamiento como económicas, además del hecho de que don Martiniano fue un fotógrafo que aprendió y mejoró su técnica conforme acumulaba experiencia en el desempeño de su oficio. Estas situaciones explican por qué algunas fotos casi no muestran movimiento o una técnica especializada en ángulos, perspectiva o efectos. Sin embargo, todas están dotadas de una enorme riqueza de contenido, que es lo que les otorga un gran valor social e histórico.

Se trata de fotos en blanco y negro, y en su mayoría presentan un plano general del cuerpo. Las personas retratadas en el estudio aparecen con poses un tanto rígidas (algunas veces sugeridas por el propio don Martiniano) ${ }^{14}$. Llama la atención que las mujeres casi siempre aparecen sentadas, con vestido o falda, con trenzas o con sus trajes típicos, a diferencia de los hombres, quienes más bien están de pie, de preferencia con sombrero, pistola, pantalones u overol (muy característico de la época). Resalta en esta sección cómo el observador —el fotógrafo- es observado por el fotografiado. Tenemos así no sólo un regreso de las miradas, sino también un encuentro simultáneo de éstas.

La segunda serie de fotos (pp. 178254) conjunta, primero, escenarios abiertos y grupos no familiares, y finaliza con documentos y otros tipos

\footnotetext{
${ }^{14}$ Hay que tener presente que en ese tiempo la duración de exposición para tomar una fotografía era más larga, a diferencia de hoy en día, que es instantánea. Para más detalles sobre este tema, un trabajo sugerente es el de Patricia Massé, "Subalternidad desentendida: ¿¿despreocupación o disimulo fotográfico?, Cuiculco, nueva época, vol. 5, núm. 13, mayo-agosto, ENAH, 1998, pp. 145-162.
}

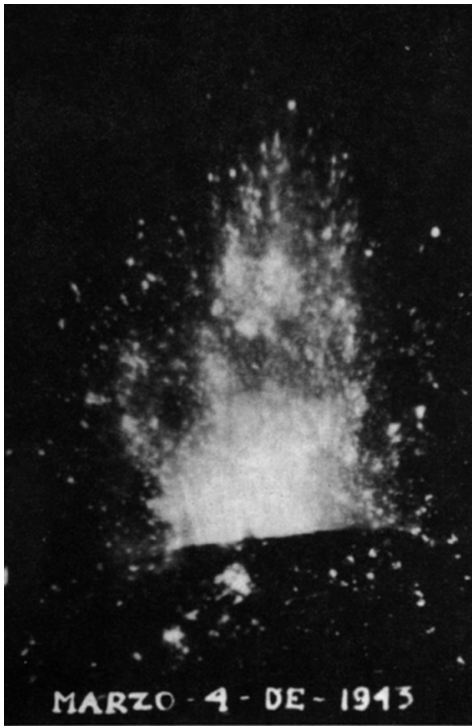

de imágenes. La particularidad de las fotografías de exteriores radica, primero, en las poses un tanto más naturales que las de estudio y en los planos panorámicos; segundo, en que resulta más fácil que surjan situaciones no planeadas, es decir, son imágenes más espontáneas. Vemos animales que se meten a media foto o niños que se ubican en lugares estratégicos para aparecer en la imagen un tanto " $\mathrm{a}$ fuerzas". Por otra parte, los horarios de trabajo "recomendables", ante la carencia de luz artificial, obligaban a que el fotógrafo y el retratado se ajustaran a las condiciones climáticas. La excepción son las fotos del volcán Paracutín en los momentos de su erupción, al parecer las únicas imágenes tomadas de noche ${ }^{15}$.

\footnotetext{
15 El contenido del libro no proporciona mayores detalles sobre cuál fue el proceso que realizó don Martiniano para lograr estas fotografías.
} 


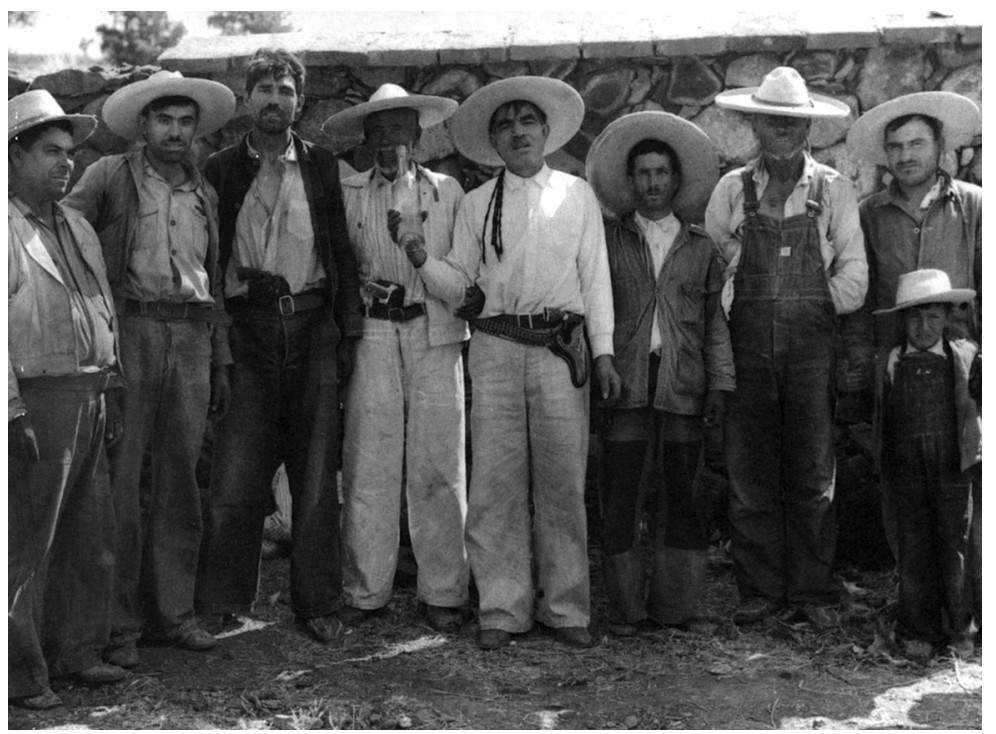

El trabajo realizado por Luis Ramírez constituye un claro esfuerzo para apelar al uso de la fotografía en el trabajo de reconstrucción microhistórica de un lugar, en este caso Villa Jiménez, Michoacán. La fotografía, como testigo ocular de los hechos, permite conocer la historia vista y registrada por don Martiniano Mendoza a través de su cámara. Sus fotos explican un poco más a los habitantes, creadores y transformadores de Villa Jiménez, al dejar un registro de las conductas humanas, los momentos y las necesidades de la vida de mujeres y hombres que habitaron ese lugar.

El autor une las piezas del rompecabezas, alterna las diversas miradas fotográficas, documentales y orales, y permite que no sólo nos detengamos en un tiempo pasado, sino que atravesemos el umbral para entrar en Villa Jiménez. En este sentido, el contenido del libro está bien logrado, aunque la ubicación del texto (prácticamente todo al inicio) puede llegar a dificultar la vinculación de éste con las fotografías por la distancia entre imágenes y comentarios. Por ejemplo, Ramírez señala en la página 163 el vidrio roto del ventanal de la escuela en una imagen de 1948, y cómo esta misma ausencia del cristal permanece quince años más tarde, en 1963. Estas observaciones se desdibujan al encontrar dichas fotos sólo hasta las páginas 211 y 212.

Es de lamentar la falta de los pies de foto o referencias. Estos factores meramente organizativos y de estructura pueden provocar, en algún momento de la lectura, lagunas o tropiezos en la hilación del tema al tener que regresar constantemente al texto o, en su caso, dificultar el hecho de que este material pueda ser consultado por cualquier persona y no necesariamente por un investigador social, lo que es uno de los objetivos del autor. En algunos momentos, Luis

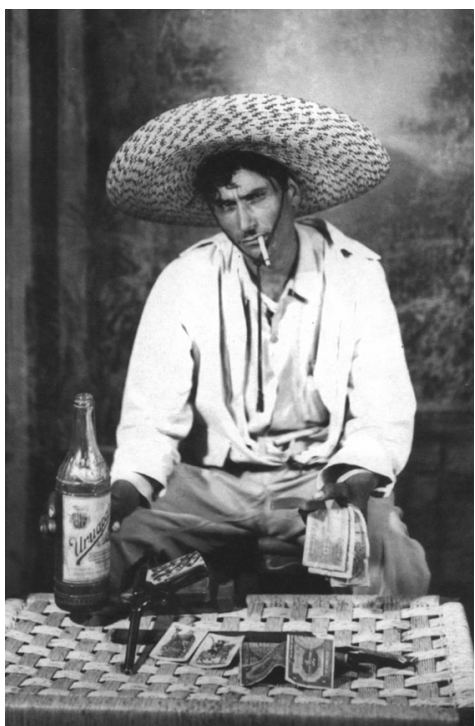

Ramírez se aleja de su papel de presentador y se vuelve intérprete, sin abundar en los datos suficientes; por ejemplo, cuando destaca los símbolos comunistas que aparecen en las fotos de Mendoza, de los que es imposible saber si fueron captados a propósito o simplemente porque ahí estaban y el fotógrafo no se fijó en ellos al momento de tomar las placas.

Finalmente, es importante mencionar que este tipo de trabajos constituye un llamado a la conservación de acervos fotográficos por su estrecha vinculación con la historia. De ahí que no sólo se trate de la necesidad de rescatarlos y preservarlos, sino también de la utilización de estos materiales en diversas investigaciones, pues permiten, como otras fuentes, una aproximación a los hechos sociales. 